\title{
Perceptions on Mentoring Concept and Mentoring Practices among Medical Mentors: A Mixed-Methods Study
}

\author{
Cheah Whye Lian ${ }^{1}$, Helmy Hazmi ${ }^{1}$, Kiu Ling Hui ${ }^{2}$, Lee Sze $\mathrm{Ee}^{2}$, Ling Wei Nii ${ }^{2}$, Veronica Wong \\ Huey Shin ${ }^{2}$ \\ ${ }^{1}$ Department of Community Medicine and Public Health, ${ }^{2}$ Faculty of Medicine and Health Sciences, Universiti \\ Malaysia Sarawak, Kota Samarahan, Sarawak, Malaysia
}

\begin{tabular}{ll}
\hline ARTICLE INFO \\
Received & $: 23 / 01 / 2015$ \\
Accepted & $: 13 / 04 / 2015$ \\
Published & $: 10 / 06 / 2015$
\end{tabular}

\section{KEYWORD}

Mentor

Mentoring

Mentee

Mentor's perception

Mentoring practices

\section{ABSTRACT}

Introduction: Mentoring medical students is one of the essential responsibilities or missions of a medical school faculty. Objective: This study aimed to determine the perceptions of mentorship and mentoring practices among mentors using a convergent parallel method. Method: Quantitative data was collected by using an adopted validated selfadministered questionnaire and analyzed using SPSS version 20. Qualitative data was done using one-to-one interview based on semi structured interview guide and analyzed using thematic analysis. Result: A total of 61 respondents participated in the quantitative survey. Approximately $75 \%$ of the respondents had 5 to 10 mentees, with majority rated themselves as satisfactory mentor. More than $60 \%$ of them met their mentees at least once every six months. Most respondents were friendly (86.9\%) and frank to their mentees $(68.9 \%)$ and were interested in their mentees' professional development $(95.1 \%)$. Phone calling $(93.4 \%)$ and E-mail $(95.1 \%)$ were preferred as modes of contact. Mentees were allowed to call their mentors anytime of the day (74.1\%). Respondents preferred to counsel their mentees $(80.3 \%)$ and would refer them for professional help whenever necessary $(70.5 \%)$. For qualitative data, a total of 5 participants participated with themes emerged: concepts of mentoring, factors contributing to ineffective mentoring and ways to improve mentoring practices. Conclusion: The respondents had positive perceptions regarding their mentorship and practices. A more structured approach with clear mentoring guideline and proper training should be in place.

(c) Medical Education Department, School of Medical Sciences, Universiti Sains Malaysia. All rights reserved.

CORRESPONDING AUTHOR: Dr Whye Lian Cheah, Department of Community Medicine \& Health Sciences, Faculty of Medicine \& Health Sciences, Universiti Malaysia Sarawak. Email: wlcheah@fmhs.unimas.my

\section{Introduction}

Mentoring was introduced and developed in many sectors with the aims to support and guide another experience-lacking individual. In medical profession, formal mentoring was only developed at the late 1900s and it has become one of the essential responsibilities of a medical school. Studies had showed that depression due to stress among medical students rated higher than other graduates in general public [1]. The burdened study load, frequent examinations, poor learning environment, and financial affairs are the common stressors among medical students that subsequently bring negative influences on their academic performance and 
general well-being. Therefore, it is important to have someone who are expert in the same field and have experiences to guide, advise, support, encourage, and direct the medical students in preparing them for their future career. For a successful mentoring relationship, mentor has the responsibility to commit time and energy on a regular and ongoing basis to ensure the welfare of the mentee (2). Mentor also possesses the role in assisting in the mentee's identity development and giving honest feedback in a constructive and caring manner [2]. There are many factors that affect the effectiveness of mentoring. Issues like difficulty in allocating meeting time, lack of available staff, lack of effort from both mentor and mentee, generation gap, matching of mentor and mentee were the common ones that caused dysfunctional mentoring relationship [2, 3, 4]. Mentors are always being regarded as the one who play the main role in a successful mentoring relationship, therefore it is important that they know their roles and responsibilities. In doing so, it is a necessity that a clear guideline on the roles and responsibilities of mentors and facilitation techniques to be in place. Apart from that, it is even better if a formal mentorship training for the faculty members to take up before they can mentor the mentees [5].

Faculty of Medicine and Health Sciences (FMHS) in Universiti Malaysia Sarawak had set up Mentor-mentee Program (MMP) since its first intake of students. Each medical student will be assigned to two mentors (one clinical and one pre-clinical mentor) to oversee them throughout the whole study duration. The objectives of MMP include promoting and assisting students in academic and professional development apart from providing positive role models. Despite the important roles of mentors and the well-defined purposes and implementation of mentor-mentee system in the FMHS, UNIMAS, there is no evaluation being formally done on mentoring system from the mentor's perspective. Mentors' perceptions and mentoring practice patterns remain unclear. This study aims to explore the concept of mentoring (qualitative research method) and to survey the mentoring profile (quantitative research method).

\section{Method}

It was a cross-sectional study using convergent parallel mixed-methods design. This method involves the collection and analysis of two independent strands of qualitative and quantitative data in a single phase to answer the research question. Quantitative data was used to explain the mentoring practices whereas qualitative data was used to explore the mentoring perceptions. The study was done among medical lecturers of Faculty of Medicine and Health Sciences of UNIMAS from October 2012 to March 2013.

The inclusion criteria consist of those participants who were at the time of study holding the position as mentor under the medical programme. Those mentor who are not in the medical programme and had less than one year of mentoring experience were excluded.

Under the quantitative data collection, a selfadministered questionnaire consists of two parts : 1) socio-demographic data; 2) 26 closed ended questions adopted from Usmani (3) that identified the mentoring profile and mentoring practices was used. A pilot study was carried out to test the questionnaire. The questions were modified to minimize ambiguity based on feedbacks, and subsequently changed to suit the local setting. A total of three questions were omitted due to redundancy and unsuitability and some of the options were modified. Questionnaires were then distributed directly to the respondents. Consent form was attached as well. Data was entered into SPSS version 20. Descriptive and inferential statistics was generated subsequently.

For qualitative data, a purposive sampling was used. To achieve adequacy of data, saturation method was used. A total of 10 semi-structured questions were used in the interview checklist. The purpose of the questions was to explore the perceptions of mentoring. A one-to-one in-depth interview was used. Consent was taken verbally prior to the interview session. Participants were approached in person and appointments were made at their convenience. Two researchers 
conducted the interview, in which one was the interviewer and the other, the note taker. Permission to record the conversation was obtained before interview. Each interview record were then transcribed verbatim. Data was explored by reading through the transcripts. This was followed by data coding, in which the texts were segmented and labelled. Themes were developed by grouping similar codes together. The whole process of data collection is presented in Figure 1.

The study was approved by the Ethics Committee of Universiti Malaysia Sarawak.

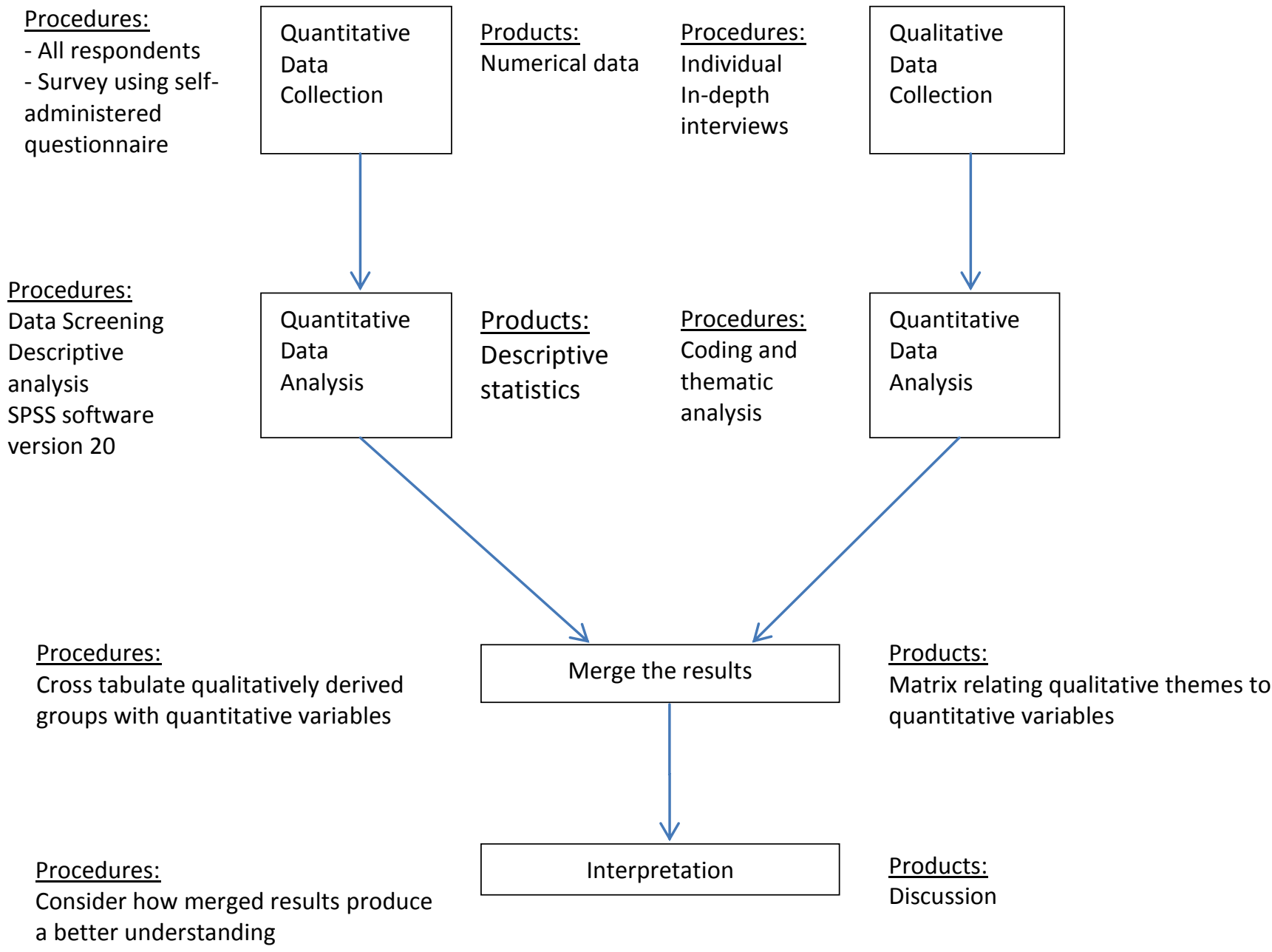

Figure 1: Diagram for a study that used the convergent design (6)

\section{Result}

A total of 61 respondents participated, contributing to a response rate of $72.6 \%$. Table 1 shows the socio-demographic background of the respondents. There was almost equal number of male and female respondents in the study, with male respondents of $50.8 \%$. There were more Malaysian respondents consisting 63.9\%. More than $50 \%$ of the respondents were clinician
Table 1: Socio-demographic Background of the Respondents

\begin{tabular}{lcc}
\hline & $\begin{array}{c}\text { Quantitative } \\
\mathrm{n}(\%)\end{array}$ & $\begin{array}{c}\text { Qualitative } \\
\mathrm{n}(\%)\end{array}$ \\
\hline Gender & $31(50.8 \%)$ & $4(80.0 \%)$ \\
$\quad$ Male & $30(49.2 \%)$ & $1(20.0 \%)$ \\
$\quad$ Female & & \\
Nationality & $39(63.9 \%)$ & $2(40.0 \%)$ \\
$\quad$ Malaysian & $22(36.1 \%)$ & $3(60.0 \%)$ \\
$\quad$ Non-Malaysian & & \\
Phase of medical programme & & \\
$\quad$ Pre-clinical (Year 1 \& 2) & $25(41.0 \%)$ & $2(40.0 \%)$ \\
$\quad$ Clinical (Year 3, 4 \& 5) & $36(59.0 \%)$ & $3(60.0 \%)$ \\
\hline
\end{tabular}




\section{Perceptions on Mentoring}

Three major themes were emerged from the quanlitative data, namely, concepts of mentoring, factors contributing to ineffective mentoring, and ways to improve mentoring practices (refer to Table 2).

Table 2: Perceptions of Mentoring

\begin{tabular}{|c|c|c|c|}
\hline Themes & Sub-themes & Findings & Anecdotes \\
\hline \multirow[t]{6}{*}{$\begin{array}{l}\text { Concepts of } \\
\text { Mentoring }\end{array}$} & $\begin{array}{l}\text { Definition of } \\
\text { mentoring }\end{array}$ & $\begin{array}{ll}\text { - } & \text { Supervising } \\
\text { - } & \text { Counselling } \\
\text { - } & \text { Advising students }\end{array}$ & $\begin{array}{l}\text { "Mentoring means I have to supervise the students." } \\
\text { (Respondent 2) } \\
\text { "Mentoring means...... when there is need to counsel } \\
\text { them or there is any need of special advice or } \\
\text { help......." (Respondent 4) }\end{array}$ \\
\hline & $\begin{array}{l}\text { Aspects of } \\
\text { mentoring }\end{array}$ & $\begin{array}{l}\text { - } \\
\text { - } \\
\text { - }\end{array}$ & $\begin{array}{l}\text { "We guide them in their studies." (Respondent } 3 \text { ) } \\
\text { "There are some students who are affected by } \\
\text { personal problem....so... the way of mentoring will } \\
\text { be slight different between those students." } \\
\text { (Respondent } 3 \text { ) }\end{array}$ \\
\hline & $\begin{array}{l}\text { Boundaries of } \\
\text { mentoring }\end{array}$ & $\begin{array}{ll}\text { - } & \text { Minor family affairs } \\
\text { - } & \text { Minor psychological } \\
\text { problem } \\
\text { - } \\
\text { Minor financial } \\
\text { problem }\end{array}$ & $\begin{array}{l}\text { "...... if they feel that they have learning problems, } \\
\text { let say, they can perhaps get some tips." (Respondent } \\
\text { 1) } \\
\text { "I think the relationship should be professional. I } \\
\text { think is not quite right for mentor to have some ... } \\
\text { intimate ... arr ... relationship with the mentees...but } \\
\text { professional yes..." (Respondent } 3 \text { ) } \\
\text { "Sometime about family..." (Respondent 5) } \\
\text { "It depends on his psychological condition. I think I } \\
\text { can solve the minor ....... and I also from } \\
\text { pharmacology, so I know some psychiatric drugs and } \\
\text { I know the psychological medicine. So, I can relieve } \\
\text { the minor problem." (Respondent } 2 \text { ) } \\
\text { "For instance, his financial, but I can solve by } \\
\text { consultation with faculty members or other } \\
\text { associations." (Respondent 2) }\end{array}$ \\
\hline & Ways of mentoring & $\begin{array}{l}\text { - } \text { Motivating } \\
\text { - } \quad \text { Encouragement } \\
\text { - Sharing of experience }\end{array}$ & $\begin{array}{l}\text { "Of course I could help it, you know, advice or } \\
\text { motivate, ..." (Respondent 1) } \\
\text { "You just motivate them." (Respondent 1) } \\
\text { "I just encourage her in some problems." } \\
\text { (Respondent 2) } \\
\text { "I share my experience on clinical examination so } \\
\text { that they can prepare for their future." (Respondent } \\
\text { 2) }\end{array}$ \\
\hline & & $\begin{array}{l}\text { - } \text { Problem solving } \\
\text { - Discussion }\end{array}$ & $\begin{array}{l}\text { "I give encouragement and solve by verbally and he } \\
\text { satisfied with it." (Respondent 2) } \\
\text { "...discuss the issue with the student and to help the } \\
\text { student to find out the solution." (Respondent 4) }\end{array}$ \\
\hline & Mode of mentoring & $\begin{array}{l}\text { - One-to-one } \\
\text { - In pair } \\
\text { - Groun }\end{array}$ & $\begin{array}{l}\text { "I prefer personally face to face or one to one." } \\
\text { (Respondent 4) } \\
\text { "Usually alone, except the two they always come } \\
\text { together." (Respondent 1) } \\
\text { "Mostly group, one to one is rarely." (Respondent 2) }\end{array}$ \\
\hline
\end{tabular}




\begin{tabular}{|c|c|c|c|}
\hline \multirow[t]{5}{*}{$\begin{array}{l}\text { Factors } \\
\text { contributing to } \\
\text { ineffective } \\
\text { mentoring }\end{array}$} & Time factor & $\begin{array}{l}\text { - Not enough time, } \\
\text { clinic hour }\end{array}$ & $\begin{array}{l}\text { "Sometimes the lecturers are quite busy doing some } \\
\text { clinical works so there may be difficult to find a time } \\
\text { for the group to meet you and your timetable also } \\
\text { packed." (Respondent } 3 \text { ) }\end{array}$ \\
\hline & Generation gap & $\begin{array}{l}\text { - More comfortable with } \\
\text { peer }\end{array}$ & $\begin{array}{l}\text { "I think more likely they go to their friends rather } \\
\text { than their mentor." (Respondent } 1 \text { ) }\end{array}$ \\
\hline & Availability of staff & - $\quad$ Lack of staff & $\begin{array}{l}\text { "You know that we are short of staff." (Respondent } \\
\text { 3) }\end{array}$ \\
\hline & Lack of effort & - $\quad$ From mentees & $\begin{array}{l}\text { "There are mentors who report that their mentees } \\
\text { never look for them." (Respondent } 3 \text { ) }\end{array}$ \\
\hline & Fear/afraid & - Afraid of mentor & "Some maybe afraid of us." (Respondent 2) \\
\hline \multirow[t]{4}{*}{$\begin{array}{l}\text { Ways of } \\
\text { improvement }\end{array}$} & Training for mentor & - $\quad$ Lectures and workshop & $\begin{array}{l}\text { "Yes, it would be nice to have like a lecture or half } \\
\text { day workshop on how to become a good mentor." } \\
\text { (Respondent } 1 \text { ) }\end{array}$ \\
\hline & $\begin{array}{l}\text { Use of } \\
\text { guidebook/logbook }\end{array}$ & - $\quad$ Logbook & $\begin{array}{l}\text { "They are supposed to meet a few times and we have } \\
\text { to sign signatures and giving comments in the } \\
\text { logbook, it may be useful." (Respondent 4) } \\
\text { "Some tips and simple techniques on how to } \\
\text { approach students with problems." (Respondent 1) }\end{array}$ \\
\hline & $\begin{array}{l}\text { Relationship } \\
\text { building }\end{array}$ & - $\quad$ Ice breaking & $\begin{array}{l}\text { "First introduction, maybe icebreaking and that } \\
\text { would be nice." (Respondent } 1 \text { ) }\end{array}$ \\
\hline & & - Informal meeting & $\begin{array}{l}\text { "Might allow them to meet as a more relax level or } \\
\text { something like that." (Respondent } 1 \text { ) }\end{array}$ \\
\hline
\end{tabular}

\section{Concepts of Mentoring}

The respondents defined mentoring as a process of supervising, counselling, and advising students. They perceived that both academic and personal matters are main aspects involved in mentoring process and the relationship among mentors and mentees should be professional. However, mentees can confide in their mentors for academic purposes, personal matters, minor family affairs, minor psychological problems, as well as minor financial problems. It is the duty of mentors to motivate, encourage, share their experiences, discuss, solve the problems and give advices when their mentees confide in them. There are three modes of mentoring in this faculty, namely one-to-one, in pairs, and in group. Respondent 1 stated that the first meeting with his mentees was being conducted in a group. For the subsequent meetings, one-by-one mode of mentoring would be carried out as mentees might need confidentiality when discussing about their academic performances or personal problems.

\section{Factors Contributing to Ineffective Mentoring}

Effective mentoring requires commitment from both sides. Respondents claimed that they were busy with their clinical works so did the mentees who were busy with their academic works. Both parties faced difficulty in allocating the time to meet each other. In their opinions, there was a generation gap between mentor and mentee. Mentees preferred to seek and share their problems with seniors and friends. Furthermore, some mentees were afraid of their mentors.

\section{Ways to Improve Mentoring Practice}

Respondent 1 suggested that activities during the orientation programs like ice-breaking and informal meeting can allow both mentor and mentee to improve their relationships. Besides, use of logbook and guidebook may improve the 
effectiveness of mentoring system in this faculty. The functions of the logbook are to record the meeting sessions and the feedbacks from mentees. Mentors should have the appropriate guidelines or guidebooks. All of the respondents perceived that training for mentors may be a good way to improve the mentoring system. This will help mentors to handle mentees' problems especially psychological problems.

\section{Mentoring Profile}

Table 3: Mentoring Profile ( $\mathrm{N}=61$ )

\begin{tabular}{lr}
\hline & $\begin{array}{r}\mathbf{n}(\%) / \\
\text { mean (SD) }\end{array}$ \\
\hline Number of mentee per mentor & $13(21.3 \%)$ \\
Below 5 & $46(75.4 \%)$ \\
$5-10$ & $2(3.3 \%)$ \\
Above 10 & $5.50(4.79)$ \\
Duration of being a mentor (year) & \\
Rate myself as a mentor & $16(26.3 \%)$ \\
Good & $39(63.9 \%)$ \\
Satisfactory & $6(9.8 \%)$ \\
Unsatisfactory & \\
Very important & $33(55.9 \%)$ \\
Important & $25(42.4 \%)$ \\
Not important & $1(1.7 \%)$ \\
Same gender mentee & $56(91.8 \%)$ \\
Sense of personal satisfaction & $60(98.4 \%)$ \\
Improvement in academic & \\
mentoring (n=57) & \\
Good & $14(24.6 \%)$ \\
Satisfactory & $42(73.7 \%)$ \\
Unsatisfactory & $1(1.7 \%)$ \\
\hline
\end{tabular}

Table 3 shows the mentoring profile of the respondents. Mentors with 5-10 mentees were the major group in the research. The mean duration of mentorship among 61 respondents is 5.5 years $(\mathrm{SD}=4.79)$. Majority of the mentors rated their mentorship as satisfactory. More than half of the respondents $(55.9 \%)$ agreed that their mentees were very important to them. More than $90 \%$ of the respondents had mentees who were of the same gender with them and gained personal satisfaction throughout their mentorship. More than two third of the respondents agreed that there was satisfactory improvement in mentees' academic achievements via mentoring.
Table 4: Mentoring Practices $(\mathrm{N}=61)$

\begin{tabular}{|c|c|}
\hline Item & n $(\%)$ \\
\hline \multicolumn{2}{|l|}{ Report of unethical issues } \\
\hline Always & $34(55.8 \%)$ \\
\hline Sometimes & $19(31.1 \%)$ \\
\hline Never & $8(13.1 \%)$ \\
\hline \multicolumn{2}{|l|}{ Reluctant in reporting cases } \\
\hline Yes & $11(18.0 \%)$ \\
\hline Sometimes & $22(36.1 \%)$ \\
\hline No & $28(45.9 \%)$ \\
\hline In contact with mentee's parents & $16(26.2 \%)$ \\
\hline \multicolumn{2}{|l|}{ Frequency of meeting } \\
\hline At least once a month & $11(18.0 \%)$ \\
\hline At least once in six months & $39(64.0 \%)$ \\
\hline At least once a year or never & $11(18.0 \%)$ \\
\hline \multicolumn{2}{|l|}{ Frank with mentee } \\
\hline Very & $42(68.9 \%)$ \\
\hline Not at all & $3(4.9 \%)$ \\
\hline Not sure at all & $16(26.2 \%)$ \\
\hline \multicolumn{2}{|l|}{ Relationship with mentee } \\
\hline Collegial & $8(13.1 \%)$ \\
\hline Friendly & $53(86.9 \%)$ \\
\hline \multicolumn{2}{|l|}{ Sharing of contact ${ }^{\mathrm{a}}$} \\
\hline Phone number & $57(93.4 \%)$ \\
\hline E-mail & $58(95.1 \%)$ \\
\hline Home address & $15(24.6 \%)$ \\
\hline \multicolumn{2}{|l|}{ Interest in mentee's well-being } \\
\hline Hobbies & $24(39.3 \%)$ \\
\hline Professional development & $58(95.1 \%)$ \\
\hline \multicolumn{2}{|l|}{ How frequent the mentee can call $(n=58)$} \\
\hline Anytime of the day & $43(74.1 \%)$ \\
\hline Office hour only & $15(25.9 \%)$ \\
\hline \multicolumn{2}{|l|}{ React if mentee violates boundary } \\
\hline Counsel & $49(80.3 \%)$ \\
\hline Scold & $4(6.6 \%)$ \\
\hline Take him/her to the dean & $9(14.8 \%)$ \\
\hline Ask for replacement & $8(13.1 \%)$ \\
\hline \multicolumn{2}{|l|}{ Handling of unsolvable problem ${ }^{\mathrm{a}}$} \\
\hline Out of my capacity & $8(13.1 \%)$ \\
\hline Ask a person who is involved directly & $12(19.7 \%)$ \\
\hline Tell him/her this is practical life & $3(4.9 \%)$ \\
\hline Refer to professional help & $43(70.5 \%)$ \\
\hline Ask for feedback from mentee & $26(42.6 \%)$ \\
\hline \multicolumn{2}{|c|}{ Willingness to sacrifice personal time to mentee } \\
\hline Most of the time & $3(4.9 \%)$ \\
\hline Sometimes & $27(44.3 \%)$ \\
\hline No & $31(50.8 \%)$ \\
\hline
\end{tabular}

\section{Mentoring Practices}

Table 4 presents the mentoring practices reported by the respondents. Majority of the respondents met their mentees at least once in six months. About one quarter of the respondents had been in contact with their mentees' parents. Majority of 
the respondents reported their relationship with their mentees to be at the friendly instead of collegial level $(86.9 \%)$. However, professional development had the highest percentage of $95.1 \%$ as the aspect of the mentor's interest in mentee's well-being.

In term of modes of contact, phone number $(93.4 \%)$ and E-mail (95.1\%) were the preferred method of communication shared by the respondents. Most of the respondents allowed the mentees to call them at any time, however only very few were willing to sacrifice their personal time for their mentees. More than $60 \%$ of respondents were very frank to their mentees in giving comments or feedbacks. Yet, less than half of the respondents asked for the feedbacks from their mentees $(42.6 \%)$.

In the aspects of roles and responsibilities, about $50 \%$ of the respondents would report the unethical issues committed by the mentees and most of them would not be reluctant in reporting cases that might harm their mentees $(45.9 \%)$. If the mentees violated boundary, for instance, behave inappropriately against their mentors, $80.3 \%$ of the respondents chose to counsel them. Reference to professional help was the most preferred option by the respondents when they were incapable of solving the problems encountered by the mentees $(70.5 \%)$.

\section{Relationship between perceptions of mentors and their mentoring practices}

After analyzing both quantitative and qualitative data, the themes and factors were merged as shown in table 5. The factors from quantitative data included roles and responsibilities of mentors and relationship between mentor and mentee. The themes from qualitative data consisted of concept of mentoring and factors contributing ineffective mentoring.

Table 5: Relationship between perceptions of mentors and their mentoring practices

\begin{tabular}{cl}
\hline Perceptions & Practices \\
\hline Concept of mentoring & Roles and Responsibilities \\
Supervising, counselling and advising & Relationship \\
Academic, professional and personal matters & Professional \\
Motivation, encouragement, discussion and sharing of & Non- professional \\
experiences & \\
Professionalism & \\
Factors contributing ineffective mentoring & \\
Time factor & \\
Lack of effort & \\
\hline
\end{tabular}

\section{Discussion}

Participants in the qualitative interview defined mentoring as a system in which mentors supervise, counsel, and advise students for particular purposes. Garmel [2] stated mentoring is a process of guiding while Usmani et al. [3] regarded mentoring as guidance, counselling and supervision which are needed to combat the stressful life among medical students. All participants agreed that the life as a medical student is challenging and will never be easy. Large volumes readings, numerous examinations and busy schedules put students under pressure. Therefore, the supervisions, advices, and guidance from an experienced mentor who went through the same medical journey are needed in the personal and professional growth of medical students.

The participants also agreed that mentoring should involve both academic and personal matters. As what Berk et al. [7] and BuddenbergFischer and Herta [8] explained personal issues can have emotional impact and thus disturb students' concentration in their academic performance. Therefore it is a synergical connection that can affect each other.

For the boundary of mentoring, the qualitative finding indicated that it should be at professional level. Violation of boundaries and physical 
relationship can definitely destroy the mentormentee relationship [9]. When it fails to define the limit for mentor-mentee relationship, for example, developing romantic relationship, or the absence of respect, the mentor-mentee relationship can be devastated. Although mentoring should be at professional level, it should not be confined to academic and personality development only. Participants agreed that they should also deal with mentees' minor family affairs, minor psychological problems, and minor financial problems, but within limit. Partly because they are not equipped with a clear guideline to what extend mentors should or should not involve in mentees' personal problems. Furthermore, a proper training should be in place to help the mentors to handle the mentees' problem. Thus, it is logical when mentors cannot help to solve their mentees' problems, the mentees would be referred to professional help.

According to the participants, during the mentoring sessions they normally will advise, motivate, encourage, share their medical practices and life experiences, solve mentees' problems as long as the problems were within their limitation, and discuss any issues brought up by their mentees. Encouragement by mentors offers a direction to mentees [10]. According to one of the participants, advices, motivations and encouragements help mentees to regain their confidences, and rebuild their self-esteem. Willing to share personal experiences and discussing extra-educational issues are those crucial characteristics in yielding an effective mentoring [11]. Discussing the topics and experiences which are not found and gained from a text book is precious and useful to a medical student. Medical practices are all about the applications of knowledge rather than just knowing the theories.

The modes of mentoring applied in this faculty are one-to-one, in pair and in group. According to Buddeberg-Fischer and Herta (8), there are four modes of mentoring, which include, one-toone, group, multiple mentors and peer mentoring. The mode of mentoring depends on the mentees' situations. When the mentees had personal problems, they often meet their mentors one-to-one to ensure privacy.

Participants found that time factor and lacking of staff had affected the effectiveness of mentoring system in this faculty. This had also been proposed by Straus et al. [4]. Out of 61 respondents, there were 36 clinical lecturers who were busy with their clinical works and thus, might not have time for their mentees. It was also difficult for the mentees to find their mentors as they had to travel or work at other hospitals or clinics. In addition, there is a generation gap between mentors and mentees. Due to this factor, some of the mentees might be afraid of their mentors. When they encountered personal issues, they were more likely to confide in their friends rather than seeking advices from their mentors. This is supported by the research done by Garmel [2], stating that peers are the one preferred to be approached by the mentees in time of difficulties.

Mentors recommended that logbooks and guidebooks are useful in improving the mentoring system in this faculty. As stated by Rowley [12], mentors need to record the activities between mentors and mentees in a logbook and they should be provided definite guidelines of their roles in mentoring in order to create a good mentoring system. The logbook can be used to ensure that the mentoring activity is being carried out while the guidebook or guideline can provide proper navigation. All participants agreed that training can be considered as a way to improve the mentoring system. According to Rose et al. [13], commitment and regular maintenance are essential to increase the effectiveness of mentoring. Mentors have to equip themselves to deal with the mentees who may face serious issues like psychological problems. One of the participants suggested that ice-breaking and informal mentoring can improve the relationship between mentors and mentees. The mentoring system should be introduced to the new intake students during their first week. Ice-breaking should be done so that the bonds between mentors and mentees can be fostered. Mentoring can be divided into formal mentoring and 
informal mentoring. Formal mentoring involves consistent meetings in office and discussion on professional topics. Unlike formal mentoring, informal mentoring is conducted in a more relaxed way and they usually share their interests and common topics.

More than $95 \%$ of the respondents had developed sense of satisfaction during their mentorship. This is in accordance to the relatively high percentage in the finding of satisfactory improvement of mentee's academic performance. Sattar and Siddiqui [14] proposed that there is a list of culminated pros for the mentors throughout their mentorship, which are, gaining satisfaction from helping mentees in need, devoting free time for different ends, getting organizational recognition and developing better job performance via widened horizons. According to the result, respondents rated themselves as satisfactory and have fulfilled their roles as a mentor.

Most of the respondents ranked their mentees as very important and important to them. This was consistent with a survey done by Usmani et al. [3] in which $95.45 \%$ of mentors agreed that their mentees were very important to them. They were obliged to guide and counsel the students with regards to academic performance especially, and personal as well as emotional development as secondary issues.

In respect to the interaction, most mentors tried to meet their mentees at least once in the six months. The meeting of mentors and mentees is an essential step in enhancing the relationship, which can ultimately ensure the success of this system. American Heart Association [15] recommended that mentor and mentee should meet at least once every one or two weeks. However, the frequency of meeting between mentor and mentee in FMHS, UNIMAS was found to be insufficient. More frequent meetings will contribute to pleasing relationship. Most of the mentees approached their mentors merely for requesting the examination results from their mentors. Lacking of time or disinclination of mentees to meet their mentors out of fear can be the factors affect the meeting.
Only a few mentors ( $\mathrm{n}=16,26.2 \%)$ actually contacted the mentees' parents. Mentees are regarded as mature enough to follow the advices and to make their own decisions. It is not obligate for mentor to contact mentee's parents unless it is necessary, for instance, informing them when the mentee involved in an accident. Most of the mentors had developed friendly relationship with their mentees. This is crucial in order to create a relaxing ambience for effective communication and better understanding [16]. Professional development was the topic brought out by most of the mentors instead of other personal interests like hobbies. A survey done by Luckhaupt et al. [17] showed that most of the time of mentor-mentee meeting was being utilized in discussing professional issues. The relationship was perceived to be professional as indicated by one of the respondents for the interview. Thus, the issues discussed were mostly related to academic and professional development or future career pathway.

The preferred modes of contact were phone calling or messaging and through E-mail. This provided a more convenient way for the mentees to contact their mentors when they were in need. Most of the mentors allowed their mentees to call them anytime. It is the role for a mentor to assist the mentees whenever possible [2]. Taherian and Shekarchian [18] proposed that face-to-face meeting with mentors complemented to the distant communication through phones or E-mail. However, mentorship is found to be time consuming $[2,18]$. Hence, most mentors were unwilling to sacrifice their personal times for the mentees. Lack of time is considered as an issue in mentoring process.

Feedbacks or comments from the mentors are fundamental in assisting mentees' in their development and improvement. Majority of the mentors of this study were very frank with their mentees. One of the positive qualities of good mentors is honesty and they are able to "give timely, appropriate, and useful feedback on skills, successes and failures" (15, p. 10). Identification of mentees' own mistakes and weaknesses and allowing them to take steps to eliminate these flaws which are important for 
further improvement. It is advisable for the mentors to get the feedbacks from their mentees for the same purposes. However, merely $42.6 \%$ of the mentors of this study asked for feedbacks from their mentees. A good mentor is "a model of a continuous learner" [12]. The desire to learn from the others, not only colleagues but also the less experience individuals like the mentees is the key element in professional growth [12]. Feedback is the best mirror for reflection on own performance in mentoring.

Various roles and responsibilities of mentor had been defined in the literatures as a guidance, counselor and advisor. Besides, mentors should play a role as good decision makers in order to bring benefits for both the faculty and the mentees. The results indicated that $55.7 \%$ of the mentors would report the unethical issues committed by the mentees and most of them would not be reluctant in reporting cases that may harm their mentees. This could prevent the mentees from committing the same mistakes and to preserve the reputation of the faculty. Counselling was the most preferred way in dealing with mentees who violated the boundaries. According to Governor's Office of Employee Relations [19], penalty should not be chosen as the first step in dealing with the wrongdoers unless counselling fails. The purpose of counselling session is to identify the root of certain issues. If the problems were unsolvable, $70.5 \%$ of mentors would refer their mentees to professional help. Psychological stress is the major problems faced by the medical students [20]. Mentors always found that they were incapable in handling serious psychological problems and thus they would refer them to psychologists for proper management.

Training is deemed to be a necessity for skill development in problem solving in various kinds of situation [18]. This can minimize the conflicts between mentor and mentee by having the guidelines regarding to the ways in solving unethical issues and other problem. Thus, training is necessary to develop an effective mentoring program [21].
Mentors perceived that mentoring is about counselling the mentees especially who are in need. Therefore, counselling is the found to be the most preferable way in solving the mentees' issues, for example, if the mentee happens to violate the boundary and behave inappropriately. However, when it comes to the issues which are hard to tackle, psychological problem for example, mentors will always refer to professional help. They agreed that professional reference is one of the ways to fulfil their responsibilities as a mentor who guides and leads their mentee to the correct and promising direction. Professionalism was being perceived to be an important element in the mentor-mentee relationship. Mentors have to deal with certain issues professionally, for instance, reporting unethical cases committed by their mentees. Although counselling is the first step in problem solving, mentors have to take alternative ways when the students continue to misbehave [19]. Being tender-hearted will not ease the problems.

Based on the perceptions of the respondents, feeling afraid towards the mentors hinders the mentees from confiding the mentors, thus may affect the effectiveness of mentoring. Besides, the respondents also suggested that relationship building helps to improve mentoring efficiency by providing a comfortable ambience to both mentors and mentees. These perceptions were reflected on the practices of the respondents who tried to be friendly towards their mentees. They claimed that the main focus of mentoring is to prepare their mentees for future career. Thus, most of the respondents developed interests in their mentees' professional development rather than personal interest like hobbies. The respondents tended to be frank with the mentees, as they realized about their responsibilities in supervising, advising and counselling their mentees in the progress of career development and achieving success. They would point out their mentees' mistakes and negative behaviors in order to help them to learn from the faults.

The frequency of meeting depends on the time factor. Both mentors and mentees are busy on their works and studies respectively. It is difficult to allocate time for the mentor-mentee 
meetings. Thus, they usually meet at least once in six months or after the academic results are announced. In order to cope with this problem, the respondents shared their contacts, including phone numbers and e-mail addresses with the mentees so that they can contact their mentors easily when they are in need. Most of them allowed the mentees to call them at any time, too. This fulfilled the characteristic of a good mentor who is always prepared to help their mentees.

\section{Conclusion}

The mentors in this study, as a whole, had positive perceptions regarding to their mentorship. They perceived mentoring as professional relationship with mentees which involved supervising and advising students. They encouraged and motivated their mentees apart from sharing their experiences during their mentorship. This study showed that there were some contributory factors that lead to unsatisfactory mentor-mentee relationship, for instance, time factor, generation gap, and lack of staff. Variation was found in the mentoring practices that create inconsistency among the respondents. Nevertheless, to improve the mentoring system, a more structured approach with clear mentoring guideline and proper training should be in place. One of the limitations of this study is response bias, which is commonly found in survey research using questionnaire. As this research is done among medical mentors in Universiti Malaysia Sarawak, the findings cannot be generalized to other medical schools or any other faculties in the university.

\section{Acknowledgement}

The authors would like to thank the respondents who have participated in this study.

\section{Reference}

1. Goebert, D, Thompson D, Takeshita J, Beach C, Bryson P, Ephgrabe K, Kent A, Kunkel M, Schechter J, Tate J: Depressive symptoms in medical students and residents:
A multischool study. Academic Medicine, 2009; 84(2):236-241.

2. Garmel GM: Mentoring medical students in academic emergency medicine. Academic Emergency Medicine, 2004; 11(12):13521357.

3. Usmani A, Omaeer Q, Sultan ST: Mentoring undergraduate medical students: Experience from Bahria University Karachi. Journal of the Pakistan Medical Association, 2011; 61(8): 790-794.

4. Straus SE, Chatur F, Taylor M: Issues in the mentor-mentee relationship in academic medicine: A qualitative study. Academic Medicine, 2009; 84(1): 135-139.

5. Keyser DJ, Lakoski JM, Lara-Cinisomo S, Schultz DJ, Williams VL, Zellers DF, Pincus HA: Advancing institutional efforts to support research mentorship: A conceptual framework and self-assessment tool. Academic Medicine, 2008; 83(3):217-225.

6. Creswell JW, Clark VLP: Designing and conducting mixed methods research. Singapore: SAGE Publications Asia-Pacific Pte. Ltd; 2011.

7. Berk RA, Berg J, Mortimer R, Walton-Moss $B$, Yeo TP: Measuring the effectiveness of faculty mentoring relationships. Academic Medicine, 2005; 80:66-71.

8. Buddeberg-Fischer B, Herta KD: Formal mentoring programmes for medical students and doctors: A review of the Medline literature. Medical Teacher, 2006; 28:248257.

9. Marks MB, Goldstein R: The mentoring triad: Mentee, mentor, and environment. The Journal of Rheumatology, 2005; 32: 216218.

10. Zerzan JT, Hess R, Schur E, Phillips RS, Rigotti N: Making the most mentors: A guide for mentees. Academic Medicine, 2009; 84: 140-144.

11. Boyle P, Boice B. Systematic mentoring for new faculty teachers and graduate teaching assistants. Innovative Higher Education, 1998; 22:157-179.

12. Rowley JB. The good mentor. Educational Leadership, 1999; 56(8): 20-22.

13. Rose GL, Rukstalis MR, Schuckit MA. Informal mentoring between faculty and medical students. Academic Medicine, 2005; 80(4): 344-348.

14. Sattar K, Siddiqui D. Why does mentoring matter? Journal of Liaquat University of Medical and Health Sciences, 2010; September- December 9(3):159-162. 
15. American Heart Association: Mentoring handbook. United States: American Heart Association, Inc; 2008

16. Jayalakshmi L, Damodar KS, Nadig P. Mentoring for medical undergraduates: Feedback from mentees (Need for training of mentors). Asian Journal of Medical Sciences, 2011; 2:151-158.

17. Luckhaupt SE, Chin MH, Mangione CM, Philips RS, Bell D, Tsevat J. Mentorship in academic general internal medicine: Results of a survey of mentors. Journal of General Internal Medicine, 2005; 20:1014-1018.

18. Taherian K, Shekarchian M. Mentoring for doctors. Do its benefits outweigh its disadvantages? Medical Teacher, 2008; 30: 95-99.

19. Governor's Office of Employee Relations. Supervisor's guide to counseling ( $3^{\text {rd }} \mathrm{Ed}$.). New York: Governor's Office of Employee Relations, 2010.

20. Sherina MS, Rampal L, Kaneson N. Psychological stress among undergraduate medical students. Medical Journal Malaysia, 2004; 59: 207-211.

21. McDonald KS, Hite LM: Ethical issues in mentoring: The role of HRD. Advances in developing human resources, 2005; 7(4): 569-582. 